\title{
USAGE OF MACHINE VISION FOR DETERMINATIN OF WORKPIECE ORIGIN
}

\author{
PAULIC, M[atej]; BALIC, J[oze] \& IRGOLIC, T[omaz]
}

\begin{abstract}
In this article we present a system for determing the workpiece origin on the CNC machine tool. Related sophisticated systems are commercially avalible on the market but they are expensive and their purchase is economically unjustified. The aim of our research is to develop an inexpensive system for non-contact determine of the starting point of the workpiece, which is sufficiently accurate and useful. Calibration procedure was developed using a feedforward neural networks. The trained neural network presents camera calibration model. When the training of neural network is complited can begin to use the system to determine the starting point of the workpiece. System has been tested on a number of prismatic shape workpieces and has been through testing proven effective.
\end{abstract}

Keywords: Neural network, image processing, milling, workpiece origin.

\section{INTRODUCTION}

Machine vision is used as a sensor for system guiding since mimics human vision and allows contactless perception of the immediate surroundings of the industrial system. The first researchers in the field of machine vision systems, describing the use of artificial visual feedback to correct the position of the robot and the accuracy of the mission, has also seen considerable development of robotic manipulators controlled directly based on artificial vision. Nowadays there are widerange of machining systems with fully integrated system of artificial vision.

The paper presents the development of the system for optical determination of workpiece origin [1] with the use of low cost equipment. The primary objective of our work was to develop a system for automatic determination of workpiece origin on desktop milling machine, which will be less expensive than similar high sophisticated systems available on the market, and its performance will be sufficiently reliable and precise at the same time. It was also incorporated in previous developed system [2-15] for intelligent programming of machine tools, using artificial methods (Neural networks, Genetic algorithms, Genetic programming, etc.).

\section{EQUIPTMENT}

The machine controls are performed by a personal computer equipped with Linux operating system, that is, through EMC2 open source CNC software package.

For the optical determination of the starting point of the workpiece it was necessary to fixed camera on the machine. An low cost QuickCam camera manufactured by Logitech (Fig. 1) was used. This camera can capture up to 30 images per second. The maximum resolution, which can be attained by the direct capturing of the video signal, is $320 \times 240$ pixels. The capturing of the video signal on the personal computer is performed via the USB (Universal Serial Bus) 2.0 interface, whereas the camera focus is regulated manually.

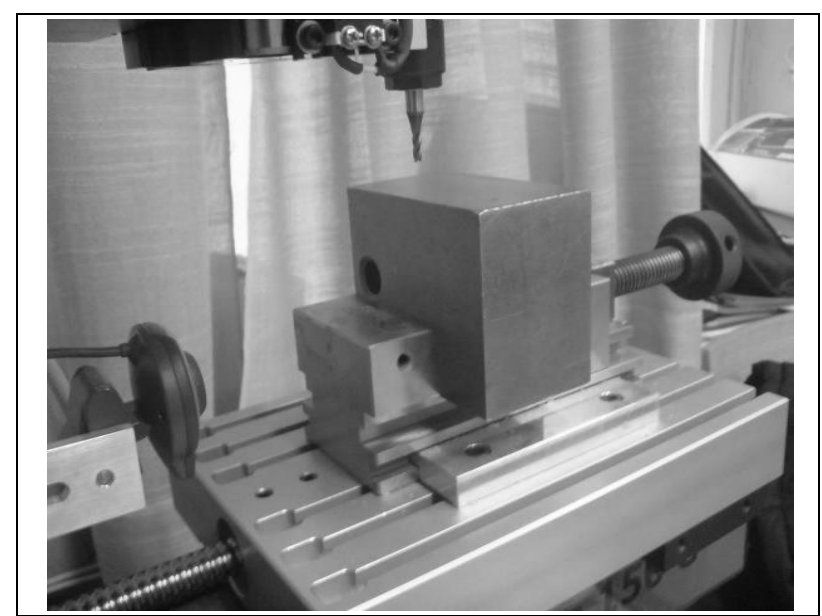

Fig. 1. Used camera and clamped workpiece on machine tool

\section{PRINCIPLE OF SYSTEM WORKING}

"Fig. 2" shows the block diagram of the basic principle of system working. First workpiece is inserted and clamped, than the system runs program to determin the zero point of the workpiece. The zero point of workpiece is determined from the capcured image with camera. Separately for each axis is calculated value of coordinate in the machine coordinate system. These values are stored in the file "stepper.war" which is a system file of EMC2 open source environment intended to storing variables that must be retained to the next system sturt-up.

Block diagram of the system for the optical determination of the zero point of workpiece is shown on "Fig. 3". When installing camera on the machine, the system must first be calibrated to determin the relationship between the coordinates of captured image and the spatial coordinates of the machine "Fig. 4". Calibration procedure [16] has a particulary important role in machine vision systems, aimed to give accurate measurments in real coordinates. Calibration is preformed once and as long as we do not change the position of camera calibration does not repeat. 


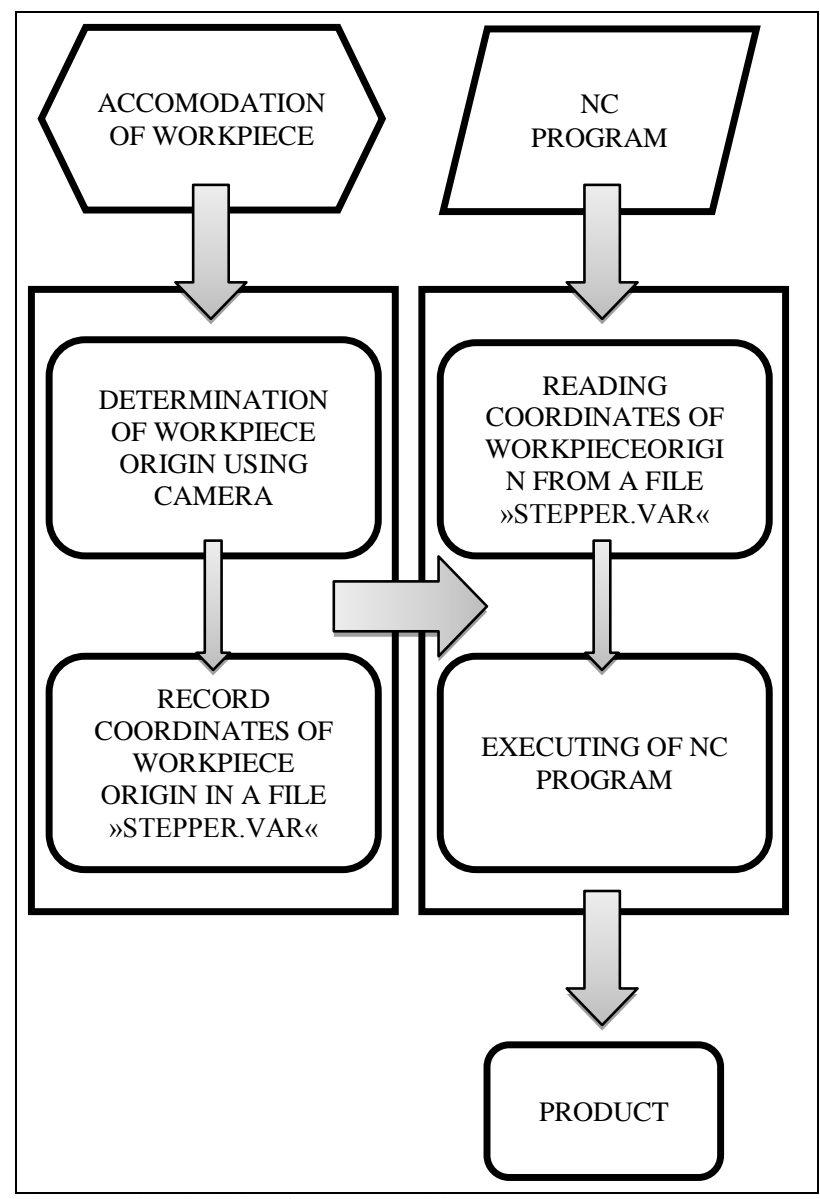

Fig. 2. Basic principle of system working

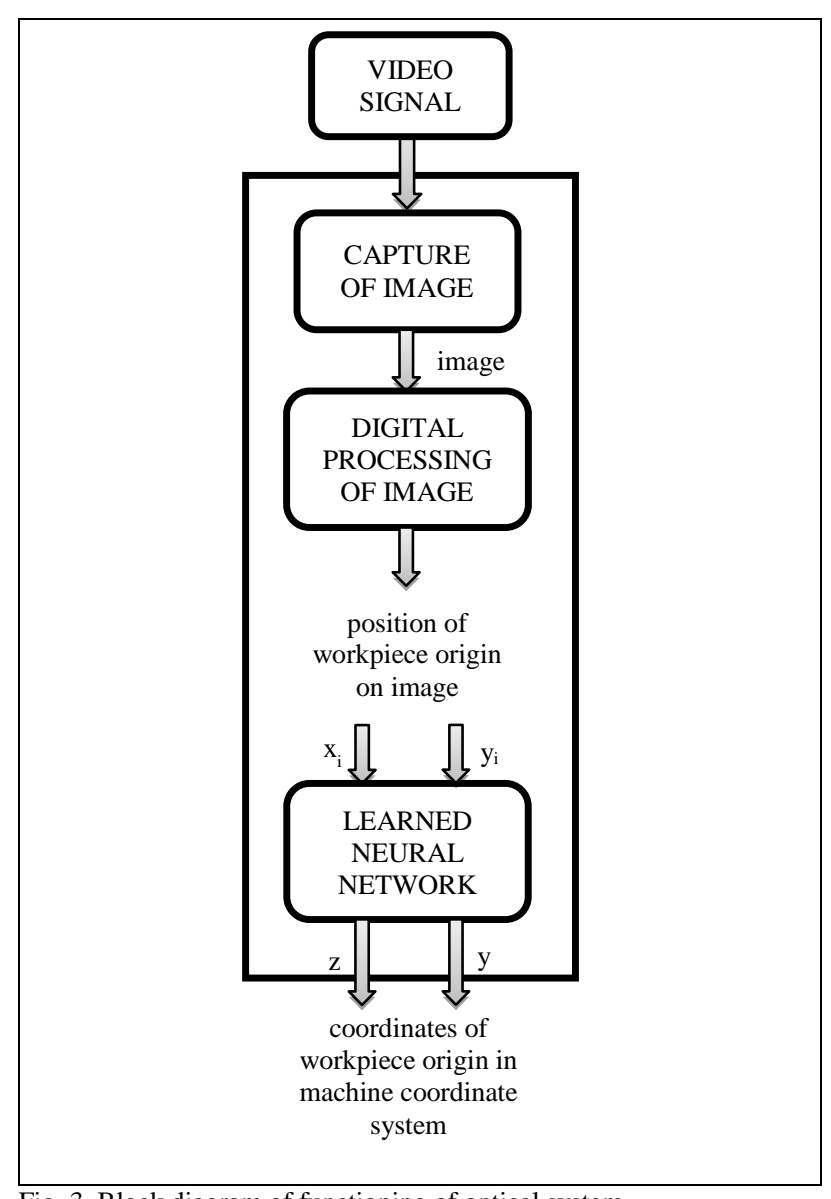

Fig. 3. Block diagram of functioning of optical system

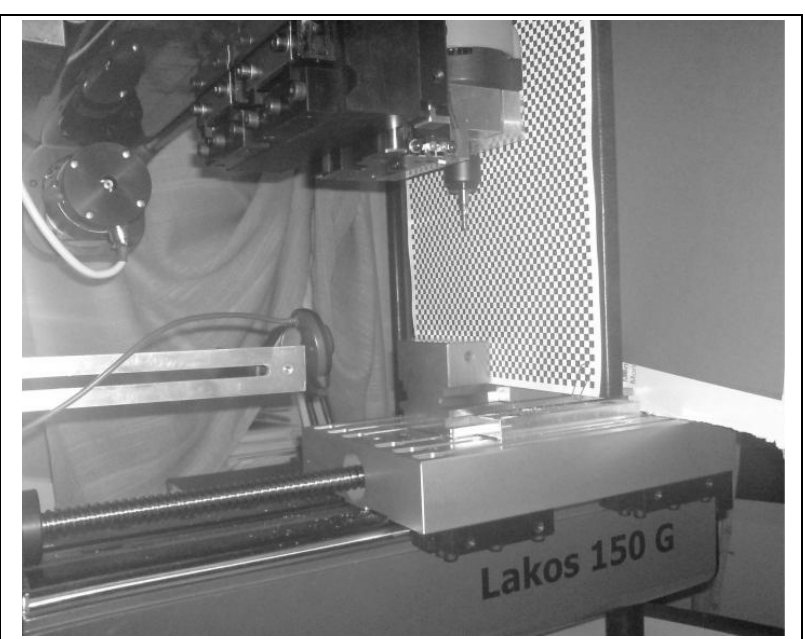

Fig. 4. Calibration of the system

Camera calibration is carried out with the help of neural network and a trained neural network represents a calibration model. When learning of neural network is complete we can begin to use the system to determin the zero point of the workpiece. Camera capture the image of fixed workpiece, in next step with appropriate algorithms extract information about the position of the workpiece origin in image coordinate system. Thise coordinates are inputs to the learned neural network, learned in the calibration phase of the system. Output from neural network obtain the information sought by the actual value of the position of the workpiece origin in the coordinate system of the machine.

\section{IMAGE PROCESSING}

With the use of suitable algorithms for processing digital image [17-23] can be obtained information of interest. In our case, we want to find a pixel in the image, which represent zero point of the workpiece. "Fig. 5" shows the procedure of image processing.

In our application we will focus on grayscale images. Color image captured by camera is transformed into grayscale (monochrome) image. This si done so that the wheighted color component of image pixels.

Treshold method is one of the simpliest and most important image segmentation procedures [2]. Using thise method distinguished looking object (in our case this is the workpiece) from background. The method is based on comparing the gray value of each pixel to a threshold value. Points on the image that exceed the threshold value is assigned the value 255 (maximum brightnes point), but if point does not exceed a threshold value, assigned value is 0 (dark point). The effectiveness of the method depends on the proper selection of threshold values, which we determined by experiments.

Edge points are simply pictorial elements arount which the brightness value has a strong vary. Strong variation of the brightness values are not only from the actual edges of objects on the image, but also siiue of noise, resulting in capturing image from camera. Task of edge detection is to find the edges of objects on the image. In our application uses Sobels algorithm for edge detection [24]. 


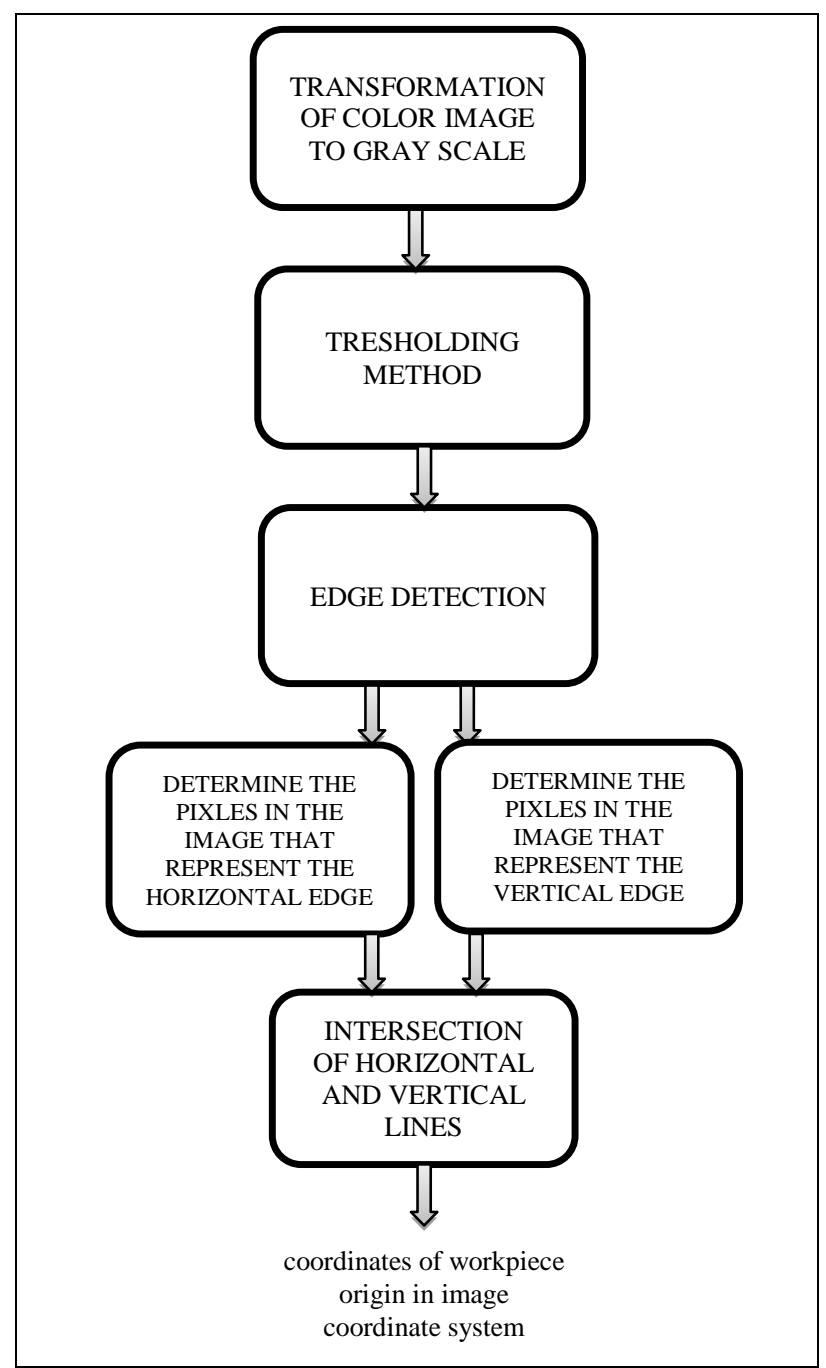

Fig.5. Block diagram of image processing

We decided to use thise algorithm because our system is placed in an enviroment with minimal noise impact (unchanged scene).

\section{RESULTS}

The system was tested with a variety of prismatic workpieces. In following text results will be presented for the optioal insertion of of the workpiece on the work table of milling machine. Before start with manufacturing, pre-calibrated camera capture image of the workpiece shown on "Fig. 6".

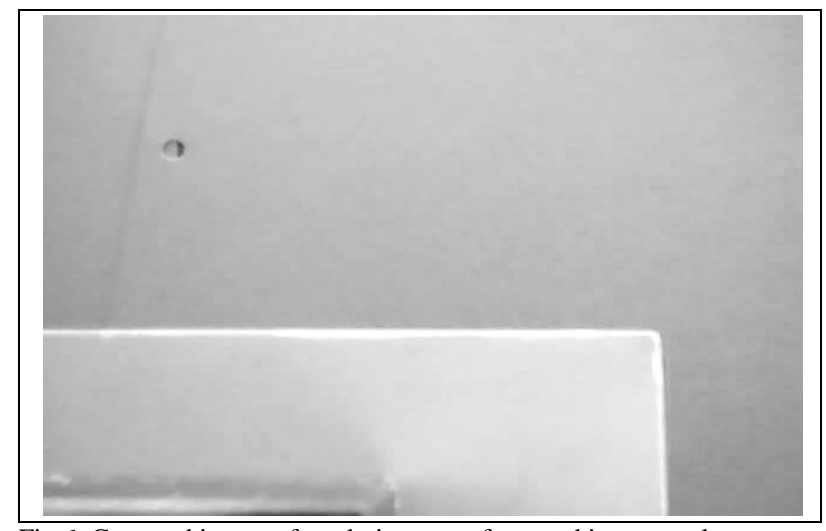

Fig.6. Captured image of workpiece transformated in grayscale
Next step in the system is to processing image with threshold method by which we distinguish an object from its background. The results of the image processed by threshold method are presented on "Fig. 7".

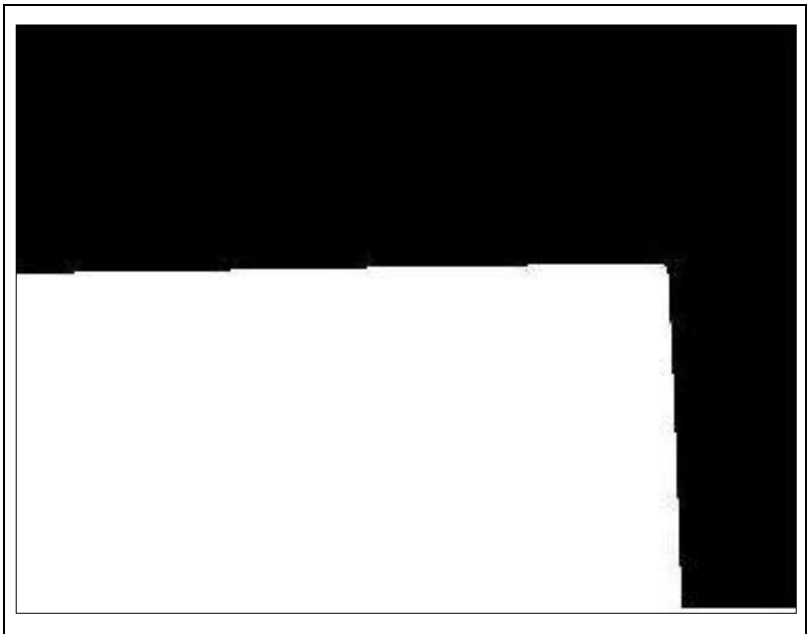

Fig.7. Image processd with Sobel algorithm

The "Fig. 8" shows the results of image processing with the Sobels algorithm for edge detection. The white color on the image represents detected edges of the workpiece.

The final result of the image processing is determined workpiece zero point, which is presented for test example on "Fig. 9". "Fig. 9" shows that the system has determined the zero point coordinates $\mathrm{x}=257.9$ and $y=135.7$ in coordinate system whose base is placed in upper left corner of the image. These values represent the inputs to the neural network, which was learnd in calibration phase and represents the relationship between image coordinates and the coordinates of the machine. Output of neural network is the zero point of the workpiece position in the machine coordinate system and for test example the system has determined that ti si workpiece zero point $\mathrm{Y}=22,692 \mathrm{~mm}$ and $\mathrm{Z}=87,149$ $\mathrm{mm}$. We run machine tool into this point and found that the system accurately determine the zero point of the workpiece.

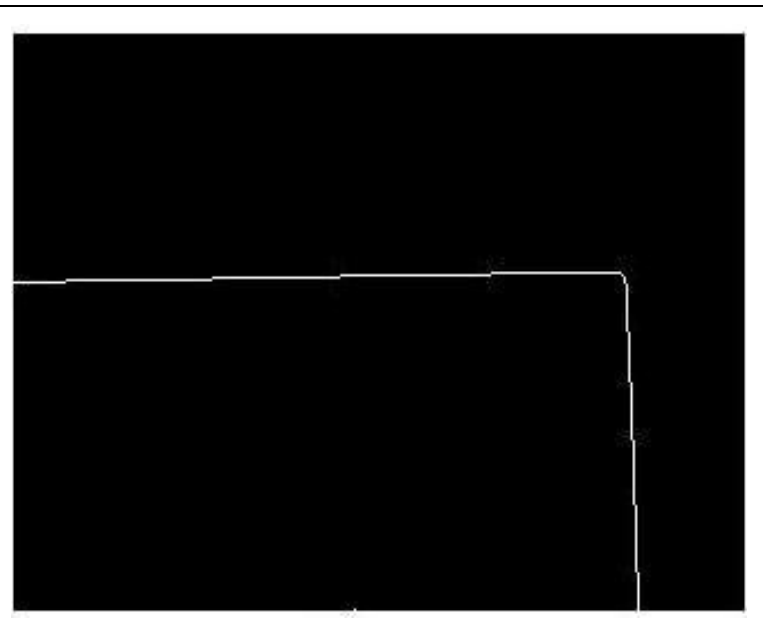

Fig. 8. Image processed with Sobels algorithm for edge detection 


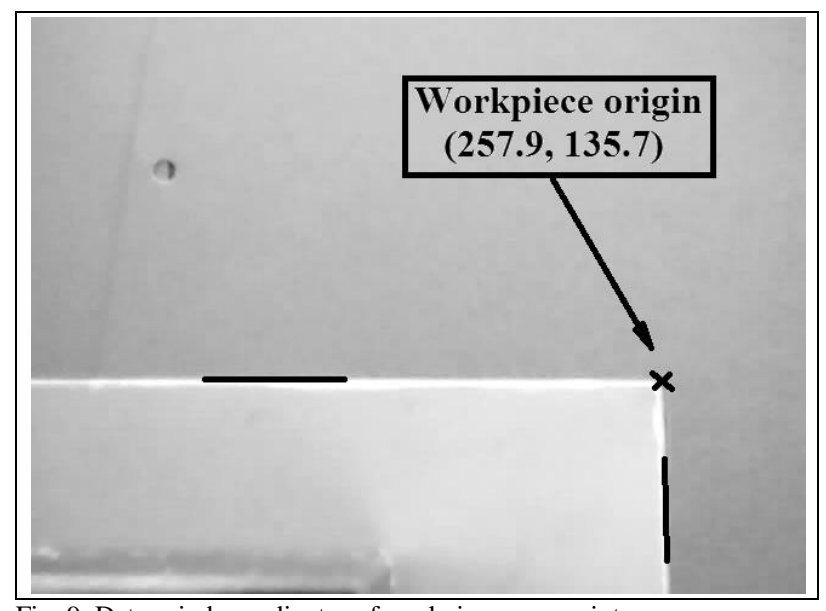

Fig. 9. Determind coordinates of workpiece zero point

\section{CONCLUSIONS}

Developed system for the optical determination of the zero pont of workpiece has been through numerous tests proved to be reliable and sutable for use in practice. Surroundings of workpiece remains generally unchanged or on the system can be installed single-colour base which allows to easily separate workpiece of background and system work is reliable and robust. In the future proper light source will be provided on the machine to illuminate the workpiece and its vicinity uniformly and continuously. It would also be suitable for practical use camera with a higher resolution.

It can be concluded that the presented system proved to be reliable and efficient to use, it is designed so that is suitable for use on other machines and devices on which would be optically determining the zero point of the workpiece useful.

\section{REFERENCES}

[1] Kamnik M. (2008). Use of the machine vision in adaptable manufacturing systems, master degree, Faculty of mechanical engineering, University of Maribor, Maribor, Slovenia

[2] Meissner K. (1994). Anwendung Genetischer Algorithmen zur Optimierung von Fertigungsprozessen, Proceedings of 5th International DAAAM Symposium, Maribor

[3] Tandon V., El-Mounayri H., Kishawy H. (2002). NC end milling optimization using evolutionary computation, International journal of machine tool and manufacture, Vol. 42, 595-605

[4] Kato K., Momochi T. (1989). Numerical controller for machining tool with learning function - combines learning program with entered program to produce resulting processing, Patent DE4011591

[5] Balic J. (2003). CNC control unit with learning ability for machining centers, Patent SI 21200 A, Patent application US 2003/0187624A1

[6] Liu Y., Zuo L., Cheng T., Wang C. (2000). Development of an open parallel intelligent $\mathrm{CNC}$ milling system: Part 1, System structure, International Journal of Advanced Manufacturing Technology, Vol. 16, 537-541

[7] Liu Y., Wang C. (1999). Neural network adaptive control and optimization in the milling process, International Journal of Advanced Manufacturing Technology, Vol. 15, 791-795

[8] Chang I., Deng J., Chan S. (2000). A next generation machining system based on NC feature unit and real-time tool path generation, International Journal of Advanced Manufacturing Technology, Vol. 16, 889-901
[9] Drstvensek I., Brezocnik M., Balic J. (1999). GA work operation determination based on feature recognition, Annals of DAAAM for 1999 \& Proceedings of the 10th International DAAAM Symposium, Vienna University of Technology, 129-130

[10] Drstvensek I., Pahole I., Balic J. (2004). A model of data flow in lower CIM levels, Journal of Materials Processing Technology, Vol. 157-158, 123-130

[11] Drstvensek I., Brezocnik M. (1999). CAP integration interface based on GA work determination operation, Proceedings of the 8th International Scientific Conference Achievements in Mechanical \& Materials Engineering AMME'99, GliwiceRydzyna-Pawłowice-Rokosowo, Poland, 189-192

[12] Chen C.L.P., Le-Clair S.R. (1994). Integration of Design and Manufacturing: Solving Setup Generation and Feature Sequencing Using an Unsupervised-Learning Approach, Computer-Aided Design, Vol. 26, 59-75

[13] De Floriani L., Bruzzone E. (1989). Building a Feature-based Object Description from a Boundary Model, Computer-Aided Design, Vol. 21, 602-610

[14] De Martino T., Falcidieno B., Giannini F., Hassinger S., Ovtcharova J. (1994). Feature-Based Modelling by Integrating Design and Recognition Approaches, Computer-Aided Design, Vol. 26, 646-653

[15] Balic J., Cus F. Vaupotic B. (2011). Intelligent automatic cuttingtool selections for turning operations, AIML-11 Conference, Dubai, UAE

[16] Gonzalez R.C., Woods R.E. (1993). Digital Image Processing, Addison-Wesley, Boston

[17] Iglesias T., Salmon A., Scholtz J., Hedegore R. (2006). Handbook of Machine Vision, Wiley-VCH, Weinheim

[18] www.ph.tn.tudelft.nl/Courses/FIP, Image processing fundamentals, Accessed on: 14.8.2011

[19] Klancnik S., Balic J., Planinsic P. (2007). Obstacle detection with active laser triangulation, Advances in production engineering \& management, Vol. 2, Issue. 2, p. 79-90

[20] Klancnik S. (2009). Obstacle detection with structured light, Proceedings of the 15th International Electrotechnical and Computer Science Conference ERK'06, Portoroz

[21] http://www.pages.drexel.edu/ weg22/can_tut.html, (2002). Canny Edge Detection Tutorial, Avtor: Bill Green (2002), Accessed on: 14.4.2009

[22] Liang R.L., Basallo, E., Looney, C.G. Image Edge Detection with Fuzzy Classifier, Proceedings of the ISCA 14th international Conference, Las Vegas, 2001

[23] Steven J., Liang I., Rogelio L., Heker L., Landers R. (2002) Machining process monitoring and control: the state-of-the-arte research, Proceedings of IMECE 2002, ASME International mechanical Engineering Congress \& Exposition, New Orleans

[24] Iglesias T., Salmon A., Scholtz J., Hedegore R. Handbook of Machine Vision, Wiley-VCH, Weinheim, 2006 